\title{
Coiling characteristics of umbilical cords in breech vs. vertex presentation
}

\section{Yifat Ochshorn, Guy Bibi, Jessica Ascher- Landsberg, Michael J. Kupferminc, Joseph B. Lessing and Ariel Many*}

Department of Obstetrics and Gynecology, Lis Maternity Hospital, Tel Aviv Sourasky Medical Center, Affiliated to Sackler School of Medicine, Tel Aviv University, Tel Aviv, Israel

\begin{abstract}
Objective: To compare selected umbilical cord parameters, especially cord coiling, between breech and vertex presentations.

Methods: We prospectively collected umbilical cords from uncomplicated breech and vertex obtained during elective term cesarean deliveries. We compared various cord parameters between the two groups as well as data regarding obstetric history and pregnancy outcome.

Results: We evaluated 55 umbilical cords from breech and 55 from vertex deliveries. Umbilical cord length (56.93 cm vs. $63.95 \mathrm{~cm}, \mathrm{P}=0.05)$, number of coils $(5.1 \pm 0.4$ vs. $11.7 \pm 0.6, P<0.0001)$ and umbilical cord index (UCI) $(0.09$ coils/cm vs. 0.18 coils $/ \mathrm{cm}, \mathrm{P}<0.0001)$ were all significantly lower for breech presentations and remained significant following multivariate analysis.

Conclusion: We document significant differences in umbilical coiling and the UCI between breech and vertex presentation. The precise reason for these differences is still unclear.
\end{abstract}

Keywords: Breech presentation; fetus; umbilical coiling index; umbilical cord; vertex presentation.

\footnotetext{
${ }^{\star}$ Corresponding author:

Ariel Many, MD

Department of Obstetrics and Gynecology

Lis Maternity Hospital

Tel Aviv Sourasky Medical Center

6 Weizmann St.

Tel Aviv 64239

Israel

Tel.: +972-3-6925633

Fax: +972-3-6925755

E-mail: many@post.tau.ac.il
}

\section{Introduction}

The human umbilical cord is a helical structure composed of three blood vessels, two arteries and one vein, surrounded by Wharton jelly. The helical nature of the umbilical vessels can be observed as early as 28 days post-conception. The final architecture can be defined by nine weeks of gestation in $95 \%$ of the fetuses $[5,13]$. The number of the coils remains constant throughout gestation [4, 13]. At term, the average cord length is 50-60 cm, and there are 10-11 coils between the fetal and placental insertion sites [7]. About $5 \%$ of the cords are uncoiled [13]. The umbilical coiling index (UCI) is calculated as the number of complete coils divided by cord length and expressed in centimeters. An abnormal UCl, either hypocoiling or hypercoiling, has been associated with adverse pregnancy outcome, including fetal structural or chromosome aberrations, fetal growth restriction, chorioamnionitis, stillbirth, premature deliveries, nonreassuring fetal heart rate patterns necessitating operative interventions, presence of meconium, and fetal acid-base abnormalities [1, 3, 6, 9, 10, 15, 20, 22].

Umbilical cord length is associated with intrauterine fetal activity, but the mechanisms that underlie umbilical cord coiling are not fully understood. Both cord vascularity and fetal factors have been implicated [7, 13, 16]. One mechanism is uneven growth of the arteries and the vein. The vein is normally longer than the arteries and is twisted around them. The arteries are normally longer than the cord itself and they are coiled within it [8]. Another factor is the mechanical forces derived from arterial pulsatility. A potential fetal factor is fetal motion which has also been linked to coiling formation, either by means of active or passive movements. This rationale is based on both human and animal studies that documented short and uncoiled umbilical cords when fetal activity was restricted [17-19, 21]. Coiling, however, may be different at different umbilical segments (the "telephone cord theory"), suggesting that fetal activity and twisting is not the only explanation for the formation of coils [2]. Fetuses in breech presentation are thought to have less motor activity compared to fetuses in vertex [25], thus, one could expect to find less coiling in breech presentations.

Umbilical cord coiling is influenced by several factors, such as fetal activity, adverse pregnancy outcome, umbilical vasculature development, and other undeter- 
mined factors. We sought to determine if there is any association between the $\mathrm{UCl}$ and fetal presentation.

\section{Materials and methods}

This prospective study was conducted during October 2005 through March 2006. Only women with uncomplicated, singleton pregnancy, who underwent elective cesarean section (CS) at term, were recruited. One study group included women who underwent elective CS due to breech presentation, and another group consisted of women who had elective CS for other indications. Women with maternal disease, whether chronic or pregnancy related (i.e., diabetes, hypertension) were excluded. Pregnancies complicated by polyhydramnios, congenital anomalies, or fetal growth restriction were also disqualified. Prior to surgery, all women had a reactive non-stress cardiotocography (CTG) and reported normal fetal movements.

We collected the umbilical cords and clamped them at the placental insertion and at the site two centimeters from the attachment to the neonate. The measurements of cord length, number of coils, and UCls were compared between the two groups. Obstetric history and pregnancy outcome parameters were also recorded, including maternal age, parity, gestational age, fetal gender, birth weight, Apgar score and arterial blood $\mathrm{pH}$.

Statistical analysis was performed using the Student's $t$-test and multivariate analysis. The ANOVA model was applied for differences, and correlations were adjusted for confounders regarding gestational age, birth weight and gravidity. A P-value of 0.05 or less was considered significant. The study was approved by the local Institutional Review Board (IRB).

\section{Results}

A total of 110 umbilical cords were collected during CS, 55 from vertex and 55 from breech deliveries. None of the patients had uterine malformations. All women in the breech group underwent a CS due to the fetal presentation. The major indication for CS in the vertex group was one or more CS in the past (28/55, 50.9\%), 20 women in the latter group (36.4\%) were operated due to maternal request (without medical indication), 3 (5.5\%) because of estimated excessive fetal weight ( $>4000 \mathrm{~g}$, not associated with diabetes), and one each $(1 / 55,1.8 \%)$ because of a low lying placenta, active herpes genitalis, pelvic fracture, and previous anal sphincter repair.

The obstetric characteristics of both groups are summarized in Table 1. Univariate analysis revealed group differences in the mean maternal age and the mean fetal weight.

The umbilical cord characteristics are presented in Table 2. Umbilical cord length, number of coils and $\mathrm{UCl}$ values were significantly lower among fetuses in breech presentation. These differences in length, number of coils and $\mathrm{UCl}$ values remained statistically significant after adjustment for maternal age and birth weight by multivariate analysis.
Table 1 Characteristics of the study population.

\begin{tabular}{lccr}
\hline & $\begin{array}{l}\text { Breech } \\
\text { mean } \pm \text { SE }\end{array}$ & $\begin{array}{l}\text { Vertex } \\
\text { mean } \pm S E\end{array}$ & $\begin{array}{l}\text { P-value } \\
t \text {-test }\end{array}$ \\
\hline Maternal age (years) & $30.4 \pm 0.61$ & $34.2 \pm 0.55$ & $<0.001$ \\
Gravidity & $1.92 \pm 0.15$ & $2.4 \pm 0.14$ & 0.015 \\
Parity & $1.56 \pm 0.1$ & $1.73 \pm 0.08$ & 0.193 \\
Gestational age (weeks) & $38.6 \pm 0.1$ & $38.8 \pm 0.11$ & 0.189 \\
Birth weight (g) & $3200 \pm 44$ & $3424 \pm 55$ & 0.002 \\
Apgar 5' & $10 \pm 0$ & $9.98 \pm 0.02$ & 0.321 \\
Umbilical arterial pH & $7.25 \pm 0.01$ & $7.25 \pm 0.01$ & 0.899 \\
\hline
\end{tabular}

Table 2 Outcome characteristics of the study population.

\begin{tabular}{|c|c|c|c|}
\hline & $\begin{array}{l}\text { Breech } \\
\text { mean } \pm S E\end{array}$ & $\begin{array}{l}\text { Vertex } \\
\text { mean } \pm S E\end{array}$ & $\begin{array}{l}\text { P-value } \\
\text { ANOVA } \\
\text { model }\end{array}$ \\
\hline Mean coil length (cm) & $56.93 \pm 1.46$ & $63.95 \pm 1.63$ & 0.05 \\
\hline Number of coils & $5.1 \pm 0.4$ & $11.7 \pm 0.6$ & $<0.0001$ \\
\hline $\begin{array}{l}\text { Umbilical coiling index } \\
\text { (UCI) }\end{array}$ & $0.09 \pm 0.01$ & $0.18 \pm 0.01$ & $<0.0001$ \\
\hline
\end{tabular}

We found a significant but a relatively poor correlation between the length of the cord and the number of coils in both groups (Pearson correlation test, $r=0.58$, $P<0.001)$.

\section{Discussion}

Differences in umbilical cord length between breech and vertex presentation have already been demonstrated by Soernes et al., who found shorter cords when the presentation was breech [21]. The clinical significance of umbilical cord coiling has also been addressed in the literature, but, to the best of our knowledge, this is the first report of an association between fetal presentation and umbilical cord coiling. Our results showed that the cords of fetuses in breech presentation were significantly shorter and less coiled and the mean $\mathrm{UCl}$ was significantly lower compared to those of fetuses in vertex presentation. Our mean UCl for fetuses in vertex presentation was similar to the mean $\mathrm{UCl}$ of 0.17 coils/cm for normal pregnancy found by van Diik et al. [26]. Since an association has been found between the $\mathrm{UCI}$ and pregnancy complications [1, 3, 6, 9, 10, 15, 20, 22], it should be emphasized that we obtained all the cords for this study from patients with uncomplicated term pregnancies and normal uterine anatomy. Also, differences in cord parameters cannot be attributed to fetal gender since the male-to-female ratio was similar in both groups.

The percentage of fetuses in breech presentation decreases with progression of pregnancy (from 25\% at 28 weeks to $3-4 \%$ at term) [11]. It is thought that the spontaneous version of fetal presentation from breech to vertex occurs as the fetus tries to accommodate itself to 
the shape of the uterus. Active body movements on the part of the fetus appear to be mandatory for this version [23]. When the uterine cavity is contracted, either due to uterine malformations or oligohydramnion, fetal activity is restricted and non-vertex presentation is more likely. Breech presentation is also associated with fetal malformations and intrauterine growth restriction, but no single cause of breech presentation can be identified in most cases [14].

Some authors have demonstrated that fetuses in breech presentation differ in patterns of activity from their vertex counterparts. Over three decades ago, Suzuki et al. analyzed fetal movements by ultrasound and concluded that frank breech presentation might result when whole body movements are weak or absent [23]. More than a decade later, Kean et al. performed a computerized analysis of heart rate and activity in fetuses in breech and vertex presentation and found that fetuses in both presentations had similar rates of movement but that breech fetuses tended to switch more often between low and high variations fetal heart rate patterns. The higher frequency of transition might indicate shorter periods of sustained activity such as that required for vertex version to occur [12]. Thus, fetal patterns of movements might be different for breech and vertex presentation. Takashima et al. found significant differences in the direction of eye movements between the two presentations and concluded that the in utero developmental course of neuronal control varies according to fetal presentation [24].

Blickstein et al. [2] suggested that umbilical cord coiling is unequal in different segments of the cords. This implies that fetal activity during the $3^{\text {rd }}$ trimester would not necessarily be a major contributor to umbilical coiling. Furthermore, if coiling is determined during the first or second trimester, a breech presentation in late pregnancy may be the consequence of an abnormal coiling process which had taken place early during gestation. Additional mechanisms such as unequal growth of vessels at the beginning of pregnancy may also have an impact on the nature and extent of umbilical coiling. It is not clear whether breech presentation at term is the consequence of "built-in" differences from a vertex presentation already existing at the beginning of pregnancy or only occurring at the end of pregnancy. It is also unclear whether coiling is the consequence or the reason for such differences.

In summary, our report documents significant differences in umbilical coiling and the $\mathrm{UCl}$ between breech and vertex presentation. The precise reason for these differences is still unclear.

\section{References}

[1] Atalla RK, Abrams K, Bell SC, Taylor DJ. Newborn acidbase status and umbilical cord morphology. Obstet Gynecol. 1998;92:865-8.
[2] Blickstein I, Varon Y, Varon E. Implications of differences in coiling indices at different segments of the umbilical cord. Gynecol Obstet Invest. 2001;52:203-6.

[3] Cromi A, Ghezzi F, Dürig P, Di Naro E, Raio L. Sonographic atypical vascular coiling of the umbilical cord. Prenat Diagn. 2005;25:851-5.

[4] Degani S, Lewinsky RM, Berger H, Spiegel D. Sonographic estimation of umbilical coiling index and correlation with Doppler flow characteristics. Obstet Gynecol. 1995;86: 990-3.

[5] de Laat MW, Franx A, van Alderen ED, Nikkels PG, Visser $\mathrm{GH}$. The umbilical coiling index, a review of the literature. J Matern Fetal Neonatal Med. 2005;17:93-100.

[6] de Laat MW, Franx A, Bots ML, Visser GH, Nikkels PG. Umbilical coiling index in normal and complicated pregnancies. Obstet Gynecol. 2006;107:1049-55.

[7] Edmonds HW. The spiral twist of the normal umbilical cord in twins and in singletons. Am J Obstet Gynecol. 1954;67: 102-20.

[8] Ente G, Penzer PH. The umbilical cord: normal parameters. J R Soc Health. 1991;111:138-40.

[9] Ercal T, Lacin S, Altunyurt S, Saygili U, Cinar O, Mumcu A. Umbilical coiling index: is it a marker for the foetus at risk? Br J Clin Pract. 1996;50:254-6.

[10] Ezimokhai M, Rizk DE, Thomas L. Maternal risk factors for abnormal vascular coiling of the umbilical cord. Am J Perinatol. 2000;17:441-5.

[11] Gabbe SG. Obstetrics: normal and problem pregnancies, 5th ed. New York NY: Churchill Livingstone, 2007.

[12] Kean LH, Suwanrath C, Gargari SS, Sahota DS, James DK. A comparison of fetal behaviour in breech and cephalic presentations at term. $\mathrm{Br} J$ Obstet Gynaecol. 1999; 106:1209-13.

[13] Lacro RV, Jones KL, Benirschke K. The umbilical cord twist: origin, direction, and relevance. Am J Obstet Gynecol. 1987;157:833-8.

[14] Luterkort M, Persson PH, Weldner BM. Maternal and fetal factors in breech presentation. Obstet Gynecol. 1984;64: 55-9.

[15] Machin GA, Ackerman J, Gilbert-Barness E. Abnormal umbilical cord coiling is associated with adverse perinatal outcomes. Pediatr Dev Pathol. 2000;3:462-71.

[16] Malpas P, Symonds EM. Observations on the structure of the human umbilical cord. Surg Gynecol Obstet. 1966;123: 746-50.

[17] Miller ME, Higginbottom M, Smith DW. Short umbilical cord: its origin and relevance. Pediatrics. 1981;67:618-21.

[18] Moessinger AC. Fetal akinesia deformation sequence: an animal model. Pediatrics. 1983;72:857-63.

[19] Naeye RL. Umbilical cord length: clinical significance. J Pediatr. 1985;107:278-81.

[20] Predanic M, Perni SC, Chasen ST, Baergen RN, Chervenak FA. Ultrasound evaluation of abnormal umbilical cord coiling in second trimester of gestation in association with adverse pregnancy outcome. Am J Obstet Gynecol. 2005; 193:387-94.

[21] Soernes T, Bakke T. The length of the human umbilical cord in vertex and breech presentations. Am J Obstet Gynecol. 1986;154:1086-7.

[22] Strong TH Jr, Elliott JP, Radin TG. Non-coiled umbilical blood vessels: a new marker for the fetus at risk. Obstet Gynecol. 1993;81:409-11.

[23] Suzuki S, Yamamuro T. Fetal movement and fetal presentation. Early Hum Dev. 1985;11:255-63. 
[24] Takashima T, Koyanagi T, Horimoto N, Satoh S, Nakano H. Breech presentation: is there a difference in eye movement patterns compared with cephalic presentation in the human fetus at term? Am J Obstet Gynecol. 1995;172: $851-5$.

[25] Tompkins P. An inquiry into the causes of breech presentation. Am J Obstet Gynecol. 1946;51:595.

[26] van Diik CC, Franx A, de Laat MW, Bruinse HW, Visser
GH, Nikkels PG. The umbilical coiling index in normal pregnancy. J Matern Fetal Neonatal Med. 2002;11:280-3.

The authors stated that there are no conflicts of interest regarding the publication of this article.

Received December 2, 2008. Revised February 3, 2009. Accepted March 26, 2009. Previously published online June 4, 2009. 